\title{
AMP-Activated Protein Kinase Signalling in Cancer and Cardiac Hypertrophy
}

\author{
Yulia Lipovka and John P Konhilas*
}

Department of Physiology, University of Arizona, Sarver Molecular Cardiovascular Research Program, USA

\begin{abstract}
The AMP-protein kinase (AMPK) pathway is very versatile as it regulates cellular energetic homeostasis in many different tissue types. An appreciation for the importance of AMPK signalling and regulation in cardiovascular and tumor biology is increasing. Recently, a link has been established between anti-cancer therapy and susceptibility to cardiac disease. It has been shown that some anti-cancer drugs lead to an increased risk of cardiac disease, underlined by de-regulation of AMPK signalling. This review explores the AMPK signalling axis in both cardiac and tumor metabolism. We then examine off-target AMPK inhibition by cancer drugs and how this may translate into increased risk of cardiovascular disease. Finally, we discuss the implication of deregulated AMPK signalling during different stages of cardiac hypertrophy. Better understanding of the molecular pathways behind pathological processes will lead to the development of more effective therapeutics for cancer and cardiovascular diseases.
\end{abstract}

Keywords: AMP-activated protein kinase; Hypertrophy; Cancer; Cardiotoxicity; Metabolism

Abbreviations: $\beta$-BD: Beta-Subunit Binding Domain; ACC: AcetylCoA Carboxylase; AID: Auto Inhibitory Domain; Akt: Protein kinase B; AMPK: AMP-Activated Protein Kinase; AMPKK: AMP-Activated Protein Kinase Kinase; CaMKK $\beta$ : Calcium-Calmodulin Dependent Protein Kinase Kinase Beta; CBS: Cystathionine $\beta$-Synthase; CPT-1: Carnitine Palmitoyl Transferase; eEF2K: Eukaryotic Elongation Factor 2 Kinase; FABPpm: Fatty Acid Binding Protein; FAT/CD36: Fatty Acid Translocase; FOXO3: Forkhead Box O3; GLUT1: Glucose Transporter 1; GLUT4: Glucose Transporter 4; GS: Glycogen Synthase; HER2: Human Epidermal Growth Factor Receptor 2; HDAC1: Histone Deacetylase 1; HIF-1a: Hypoxia-Inducible Factor 1 Alpha; LKB1: Liver Kinase B1; LVH: Left Ventricular Hypertrophy; MO25: Mouse Protein 25; mTOR: Mammalian Target of Rapamycin; mTORC1: Mammalian Target of Rapamycin Complex 1; PCr: Phosphocreatine; PFK 2: 6-phosphofructo-2-Kinase; PP2A: Protein Phosphatase 2A; PP2C: Protein Phosphatase 2C; p300: Histone Acetyltransferase p300; ROS: Reactive Oxygen Species; RTK: Receptor Tyrosine Kinase; SIRT1: Sirtuin 1; STRAD: Ste-20-Related Adaptor Protein Complex; TNFa: Tumor Necrosis Factor Alpha; TSC2: Tuberculosis Sclerosis 2

\section{Molecular Structure of AMPK}

AMP-activated protein kinase (AMPK) is a heterotrimeric complex composed of a catalytic a subunit and regulatory $\beta$ and $\gamma$ subunits. Each subunit has at least two different isoforms, which are encoded by distinct genes. They differ slightly in their structure and have differential expression patterns across tissues. The a subunit exists as 2 isoforms ( $\alpha 1$ and $\alpha 2$ ), contains the AMPK serine/threonine kinase domain, and is phosphorylated on at least three residues [1-3]. Phosphorylation of threonine 172 by upstream kinases is essential for AMPK activity, and is often used as an indicator of the activation state of the kinase [4]. Other phosphorylation sites are Thr258 and Ser485, but their contribution to AMPK activity remains to be elucidated [5].The a subunit also has an auto inhibitory domain (AID). The AID interacts with the kinase domain and together they undergo a conformational change in response to AMP interaction with the $\gamma$ subunit, contributing to AMPK activation [6-8]. AMPKa1 only shares $77 \%$ sequence identity with the AMPKa2 isoform [9]. AMPKa1 is primarily found in secreting cells, while AMPKa2 is mainly expressed in skeletal and heart muscle [10].

The $\beta$-subunit of AMPK bridges $\alpha$ - and $\gamma$-subunits by means of its C-terminal sequence. Its function is not limited to holding the AMPK heterotrimer together, since it contains a central non-catalytic glycogen-binding domain, which senses the status of cellular energy reserved in the form of glycogen [11]. Binding of glycogen with a single glucose $\alpha 1-6$ branch to the $\beta$ subunit of AMPK allosterically inhibits phosphorylation of $\alpha$ subunit by upstream kinases [12].

AMPK $\beta$-subunit has two isoforms, $\beta 1$ and $\beta 2$, that only differ in the first 65 of 275 residues [13]. Despite high structural similarity, they have differential tissue distribution; with $\beta 1$ being expressed in a wide range of tissues and $\beta 2$ primarily localized to brain, kidney and striated muscle [14].

The $\gamma$ subunit can be found as 3 isoforms $\left(\gamma 1, \gamma^{2}\right.$ and $\left.\gamma^{3}\right)$ and is made out of four cystathionine $\beta$-synthetase (CBS) motifs that pack together generating two Bateman domains (CBS1 + 2 and CBS3 + 4). The symmetry of the CBS domains creates four potential adenylbinding sites [15]. The 2' and 3' hydroxyl groups of each AMP ribose groups interact with an aspartic acid residue located on the first turn of the $\alpha$-helix adjacent to the site. In the fourth potential adenyl-binding site, an arginine residue is substituted instead, which probably makes AMP binding to this domain impossible. So, mammalian AMPK binds three AMP molecules; one binds to "site 4" and does not exchange for ATP and co-purifies with the proteins since it is tightly bound. The other two AMP molecules compete for binding with Mg-ATP and/ or ATP to sites " 1 " and " 3 " and are responsible for adenyl-sensing properties of the mammalian enzyme [16].

*Corresponding author: John P Konhilas, Department of Physiology, University of Arizona, Sarver Molecular Cardiovascular Research Program, Medical Research Building, Room 320 Tucson, AZ 85721-0241,USA, Tel: (520)-626-6578; Fax: (520)-626-7600; E-mail: konhilas@arizona.edu

Received July 31, 2015; Accepted August 24, 2015; Published August 31, 2015

Citation: Lipovka Y, Konhilas JP (2015) AMP-Activated Protein Kinase Signalling in Cancer and Cardiac Hypertrophy. Cardiovasc Pharm Open Access 4: 154 doi:10.4172/2329-6607.1000154

Copyright: () 2015 Lipovka Y. This is an open-access article distributed under the terms of the Creative Commons Attribution License, which permits unrestricted use, distribution, and reproduction in any medium, provided the original author and source are credited. 
The $\gamma$ isoforms have the greatest structural variability among all AMPK subunits. The most widely expressed isoform is $\gamma 1$, composed of 331 residues [17]. The $\gamma 2$ subunit is 569 -residues long and is mainly expressed in the heart, brain, placenta and skeletal muscle [3]. The third isoform $\gamma 3$, is composed of 489 residues and is only expressed in skeletal muscle [17]. A schematic representation of the three AMPK subunits is presented in Figure 1. Detailed examinations regarding the quaternary structure of AMPK can be found in several studies $[9,16,18]$.

\section{Mechanisms of AMPK Activation}

AMPK activity is regulated in response to the cellular energy state, which is reflected in the ratio of AMP to ATP. During energy usage, ATP is broken down to generate ADP, which can be converted to AMP through the action of adenylate kinase. Binding of AMP facilitates phosphorylation of the activation loop at Thr172 by AMPK kinase (AMPKK) and reduces the dephosphorylation rate of AMPK by the PP2C-a phosphatase [19]. AMP binding to AMPK induces allosteric and conformational changes that affect the interaction between the kinase and the autoinhibitory domains of AMPKa [7,20]. AMP, as the primary activator of AMPK, has a much greater affinity to AMPK than that of ATP even when the cellular concentrations of ATP are much greater than those of AMP. In addition to AMP, ADP can also bind to AMPK, protecting the enzyme from dephosphorylation [10].

The phosphorylation state of Thr172 reflects the activation status of AMPK and is influenced by the balance between the action of upstream kinases and protein phosphatases. So far, two AMPKKs have been identified: Calcium-calmodulin dependent protein kinase kinase $\beta$ (CaMKK $\beta)$ [21] and the tumor suppressor kinase complex LKB1 $[22,23]$. The LKB1 complex consists of LKB1 and two accessory subunits, STRAD and MO25, both of which are required for LKB1 activity (Figure 2) [22-24]. There are at least two protein phosphatases that can inhibit AMPK activation: protein phosphatase 2A (PP2A) and protein phosphatase 2C (PP2C). PP2A inhibits AMPK phosphorylation in response to increase in intracellular calcium concentrations [25]. It is not clear what drives PP2C action on AMPK, but alterations in PP2C expression modulate AMPK activation in the heart [26].

In addition to phosphorylation, AMPK can be post-translationally modified by acetylation on its a subunit. Acetylation state of AMPKa is determined by opposing catalytic activities of HDAC1 and p300. Deacetylation enhances the catalytic activity of AMPK by promoting its association with the upstream kinase LKB1 [27]. Post-translational modifications also occur on the regulatory subunits of AMPK. The $\beta$ subunit can be modified by $\mathrm{N}$-terminal myristoylation of the Gly2 residue. It has recently been proposed that AMP dependent phosphorylation of Thr172 depends on the $\beta$ subunit of AMPK being myristoylated [28].

\section{AMPK is Central to Healthy and Pathological Metabolism}

\section{AMPK in cardiac metabolism}

Fatty acids are the preferred substrate for energy production in the heart [29]. AMPK modulates cardiac fatty acid metabolism in several ways. As part of this regulatory pathway, AMPK targets and phosphorylates acetyl-CoA carboxylase activity (ACC) inhibiting ACC activity [30,31]. Because ACC catalyses the carboxylation of acetyl-CoA to produce malonyl-CoA, which is a substrate for the biosynthesis of fatty acids, inhibition of ACC activity decreases fatty acid biosynthesis. A major point of regulation of fatty acid oxidation lies in the ability to transport the long-chain fatty acyl-CoA from the cytosol into the mitochondria where it is oxidized to form acetyl-CoA. The rate-limiting enzyme in this process is carnitine palmitoyltransferase (CPT-1). CPT-1 catalyses the transfer of the fatty acyl group from acyl-CoA to carnitine, preparing it for transport from the cytosol into mitochondria. Malonyl-

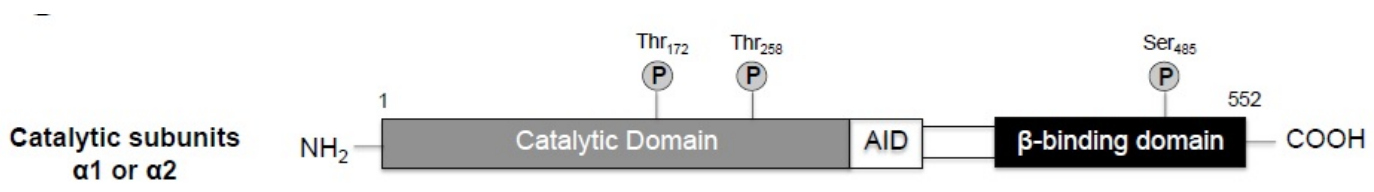

Regulatory subunits $\beta 1$ or $\beta 2$
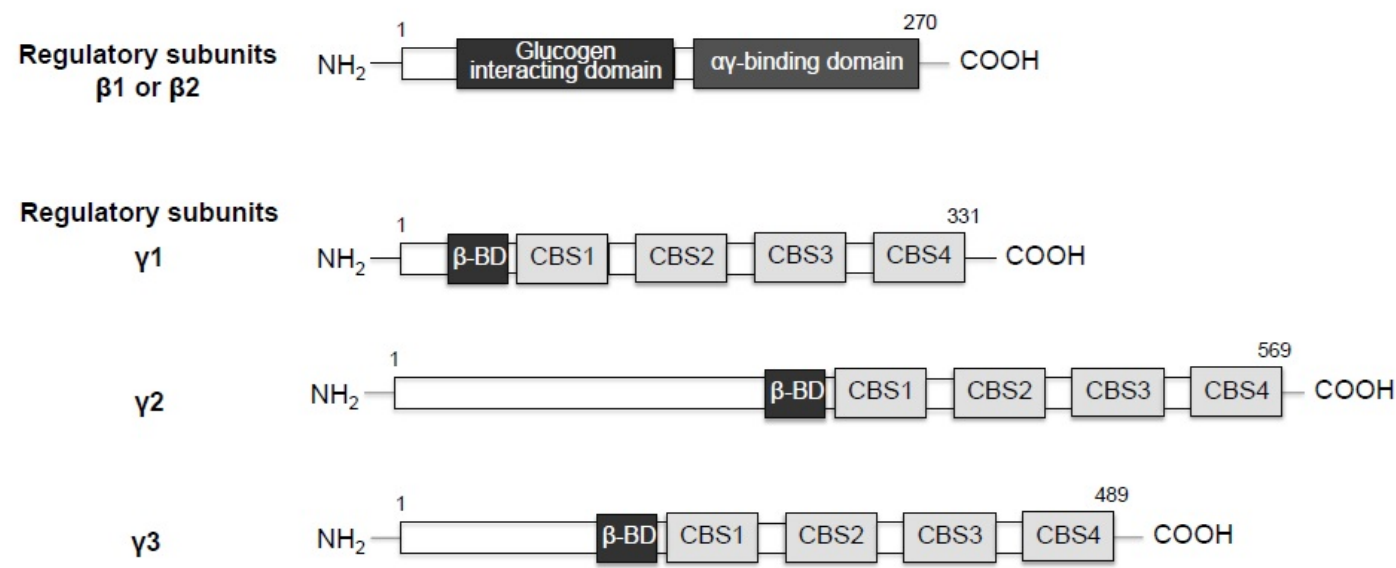

Figure 1: Structure of AMP-activated protein kinase (AMPK). Domain composition of the catalytic ( $\alpha$ ) and regulatory ( $\beta$,, ) subunits of AMPK. Phosphorylation sites are shown on the $\alpha$-catalytic subunit. AID: Auto Inhibitory Domain, CBS: Cystathionine $\beta$-Synthetase Motif, $\beta$-BD: $\beta$-subunit Binding Domain. This representation does not accurately reflect the relative lengths of the subunits and their domains. 


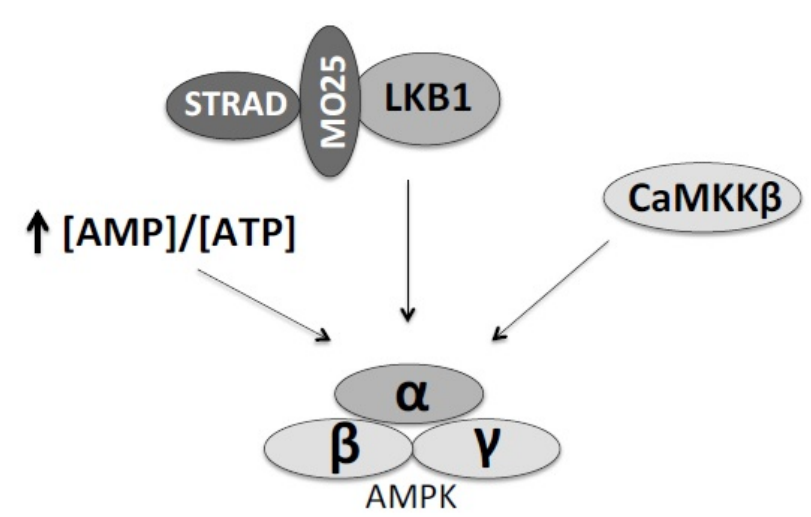

Figure 2: Mechanisms of AMPK activation. AMPK is activated in response to an increase in intracellular AMP/ATP ratio, as well as after phosphorylation of its a-catalytic subunit by upstream kinases. The two kinases that phosphorylate AMPK are LKB1, which forms a complex with two accessory proteins STRAD and MO25, and CaMKK $\beta$.

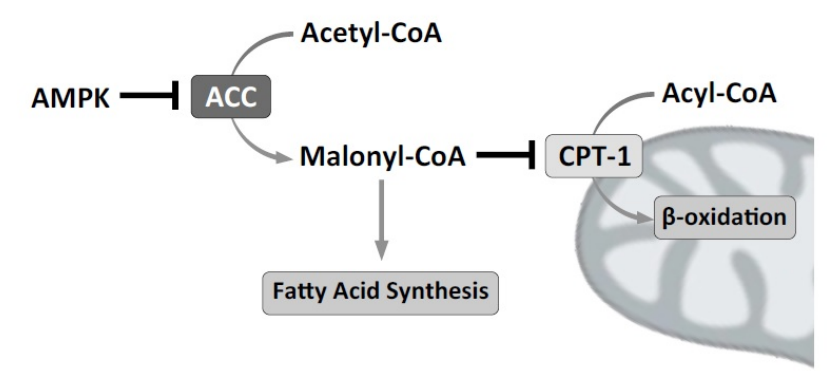

Figure 3: AMPK regulates fatty acid synthesis and $\beta$-oxidation. AMPK is a negative regulator of Acetyl-CoA carboxylase (ACC) activity. Active ACC catalyzes the conversion of Acetyl-CoA in Malonyl-CoA. Malonyl-CoA allosterically inhibits carnitine palmitoyltransferase-1 (CPT-1), which catalyzes the transfer of the fatty acyl group from acyl-CoA to carnitine, preparing it for transport from the cytosol into mitochondria, where is used for $\beta$-oxidation.

CoA allosterically inhibits CPT- 1 activity, impairing the $\beta$-oxidation of fatty acids [32]. In summary, ACC inhibition by AMPK decreases malonyl-CoA levels promoting fatty acid transport into mitochondria and increases $\beta$-oxidation rates (Figure 3 ).

AMPK also controls fatty acid transport across the cell membrane in cardiomyocytes. AMPK activation stimulates the expression of fatty acid binding protein (FABPpm) [33]. It also elevates the expression and translocation of the fatty acid transporter FAT/CD36 from intracellular stores to the plasma membrane [34]. Lastly, AMPK stimulates mitochondrial biogenesis, by yet not fully understood mechanisms [35].

Another pool of ATP production in the heart is generated by glucose metabolism. AMPK increases glucose uptake by enhancing glucose transporter 4 (GLUT4) and GLUT1-mediated transport [3638]. AMPK can also phosphorylate 6-phosphofructo-2-kinase (PFK 2), an enzyme responsible for regulation of glycolysis and gluconeogenesis. The result is a net increase in glycolysis during states of energetic stress such as occurs during myocardial ischemia or exercise [39,40]. AMPK also influences glucose storage, by phosphorylating and inactivating glycogen synthase (GS), thus promoting glucose flux through glycolysis $[41,42]$. A summary of the metabolic pathways affected by AMPK in the heart is presented in Figure 4A.

\section{AMPK in tumor metabolism}

The link of AMPK signalling to cancer dates back to the discovery of LKB1. LKB1 was first identified as a tumor suppressor mutated in an inherited cancer susceptibility known as Peutz-Jegher's syndrome $[43,44]$. More recently, it has also been linked with certain types of breast cancer [45]. It is not surprising that AMPK signalling is implicated in cancer metabolism considering that tumor cells must adjust their metabolism to generate the energetic and biosynthetic intermediates required to support increased cell division in the context of stress, such as hypoxia and nutrient deprivation [46]. Fundamental changes in cancer metabolism include a switch to aerobic glycolysis, known as the Warburg effect [47] and increased use of glutamine for mitochondrial-dependent ATP production [48]. AMPK and LKB1 are both negative regulators of aerobic glycolysis. Loss of LKB1 or AMPK activity promotes enhanced glucose and glutamine metabolism, boosting growth and biosynthetic capacity of tumor cells, by increasing HIF-1a expression $[49,50]$.

Activation of the LKB1/AMPK pathway can sometimes give the cells the selective advantage to proliferate, and explains why in some cancers, increased AMPK activity is associated with poor prognosis [51,52]. AMPK can promote metabolic adaptation that supports tumor growth. During energy stress, the generation of NADPH by the pentose phosphate pathway is impaired. AMPK activation at low intracellular ATP levels induces alternative routes for NADPH generation. This is achieved by inhibiting ACC and therefore maintaining NADPH levels by decreasing its consumption in fatty-acid synthesis and increasing its generation by means of fatty acid oxidation $[53,54]$. AMPK can also activate the eukaryotic elongation factor 2 kinase (eEF2K), which confers cell survival under acute nutrient depletion by blocking translation elongation [55]. In aggressive experimental breast cancer tumors, AMPK activation supports tumor glucose metabolism through positive regulation of glycolysis and the non-oxidative pentose phosphate cycle [56]. The dual role of AMPK signalling in cancer cell metabolism is presented in Figure 4B.

\section{AMPK is a Tumor Suppressor}

Reduced AMPK activation is associated with worsening overall prognosis in many cancers and is sometimes linked to increased metastasis [57-59]. An outcome of reduced AMPK signalling is increased cell proliferation irrespective of the molecular energy levels. This is achieved through uncontrolled activation of the mTOR pathway. Under normal conditions, AMPK inhibits mTORC1 signalling by direct phosphorylation of TSC2 [60] and the mTORC1 regulatory subunit, Raptor [61]. LKB1/AMPK dependent inhibition of the mTOR pathway acts as a tumor suppressor in transformed cells, contributing to cell growth inhibition and repression of oncogenic mRNA translation in response to energy stress [62,63]. AMPK tumor suppressor potential also acts through the Akt/FOXO3 signalling axis. Activated AMPK reduces Akt mediated phosphorylation of FOXO3a, activating this transcription factor and leading to inhibition of tumor growth. Reduction of Akt activity also prevents the epithelialmesenchymal transition of cancer cells, thereby preventing invasion of basement membranes leading to metastasis $[64,65]$.

The tumor suppressor gene p53 is mutated in many cancers and loss of its function is associated with bad prognosis. Recently, a link between AMPKa2 subunit isoform expression and p53 activation has been established. AMPK $\alpha 2$ levels are suppressed in several tumors, including breast cancer when compared to their healthy counterparts [66]. When AMPKa2 expression is restored in those cells, it promotes 
A

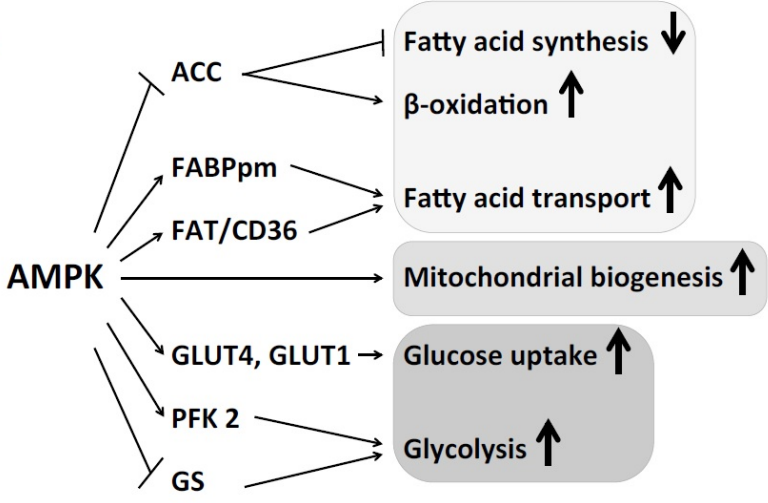

B

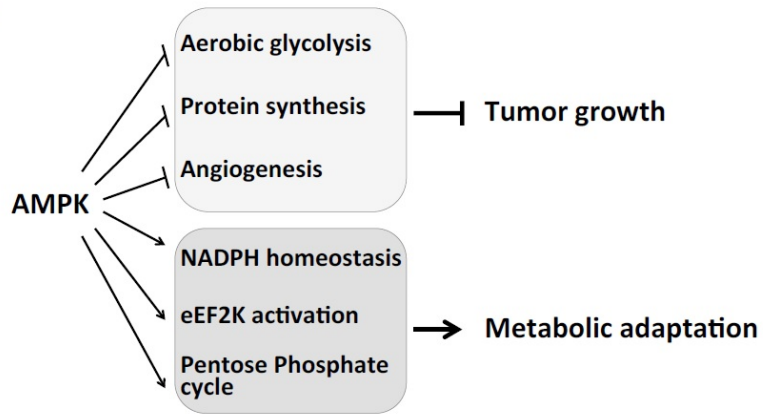

Figure 4: AMPK regulates cardiac and tumor metabolism. (A) A schematic representation of the metabolic processes in the heart affected by AMPK and the molecular targets that mediate those effects. ACC: Acetyl-CoA Carboxylase, FABPpm: Plasma Membrane Fatty Acid-Binding Protein, FAT: Fatty Acid Translocase, GLUT4: Glucose Transporter type 4, GLUT1: Glucose Transporter type 1, PFK 2: Phosphofructokinase 2, GS: Glycogen Synthase. (B) A summary of the metabolic pathways affected by AMPK in tumor cells. AMPK can inhibit tumor growth by blocking the metabolic switch to aerobic glycolysis, blocking protein synthesis and reducing angiogenesis. On the other side, AMPK can promote metabolic adaptation of cancer cells by regulating $\mathrm{NADPH}$ homeostasis, activating eEF2K and stimulating non-oxidative pentose phosphate cycle.

p53 acetylation via inhibiting the deacetylase activity of SIRT1. This increases p53 stability and induces apoptosis in tumor cells [67].

\section{Off-Target Inhibition of AMPK by Cancer Drugs Increases the Risk of Cardiac Disease}

Cardiotoxicity is one of the adverse effects of cancer treatment. The most common form of cardiotoxicity is cardiomyopathy associated with the use of anthracyclines as chemotherapeutic agents [68]. The mechanisms behind anthracyclines cardiotoxicity are well studied. A widely accepted mechanism of this cardiotoxicity is through formation of reactive oxygen species (ROS) leading to oxidative stress [69]. However, alternative mechanisms of cardiotoxicity have been proposed. One example is deregulation of cardiac AMPK activity. Anthracyclines, such as doxorubicin, cause cardiac damage by accelerating myofilament apoptosis, suppressing myofilament protein synthesis and altering cardiac energy metabolism [70]. The latter is achieved by decreasing phosphocreatine (PCr)/ATP, AMPK expression and activation [71,72].

Cancer "targeted therapies", including drugs that inhibit tyrosine kinases, are also cardiotoxic. The majority of pharmacological protein kinase inhibitors are competitors for ATP binding. More than 500 protein kinases possess an ATP-binding site [73]. Because of this, many of the kinase targeting drugs are highly non-specific, and can target several different kinases. This lack of target specificity makes many organ systems susceptible to the toxic effects of anti-cancer drugs in addition to the heart.

To date, two receptor tyrosine kinase (RTK) inhibitors (Sunitib and Herceptin) have been reported to negatively impact cardiac AMPK signalling. Sunitib, a drug used to treat renal and gastrointestinal cancer, causes left ventricular dysfunction [74]. More recently it has been shown to induce myocyte injury in-vivo, reduce ATP concentration in cardiomyocytes and impair AMPK's ability to phosphorylate downstream targets in the cell [75]. These findings suggest that off-target inhibition of AMPK accounts, at least in part, for Sunitib cardiotoxicity. Herceptin (trastuzumab), used to treat HER-2 positive breast cancer, impairs cardiac AMPK activation resulting in failure to induce stress-related survival mechanisms [76]. It also lowers intracellular ATP levels in cardiomyocytes, leading to apoptosis, which is further aggravated by TNFa [77].

As mentioned above, some anti-cancer medications that show cardiotoxicity have an inhibitory effect on cardiac AMPK signalling. AMPK is central to the energetic homeostasis of cardiac cells. A decrease in AMPK activation capacity causes a misbalance in energy handling, which could lead to the development of cardiac pathologies, such as hypertrophy. It is therefore important to consider accompanying cancer therapies that would counteract the cardiotoxic effects of anti-cancer agents, with a special focus on balancing cardiac AMPK signalling.

\section{AMPK Signalling is Implicated in the Initiation and Progression of Cardiac Hypertrophy}

Cardiac hypertrophy is a thickening of the heart muscle, which results in a decrease in size of the chamber of the heart, including the left and right ventricles. It is considered an adaptive response of the heart to a number of disease etiologies. The changes in cardiac mass as a result of hypertrophy are associated with changes in cardiac metabolism, which slowly changes its preference for ATP production from fatty acids to carbohydrates, as hypertrophy progresses [78].

Decreased AMPK signalling is associated with an increased risk of developing cardiac hypertrophy. In terms of molecular changes, cardiac hypertrophy is denoted by enhanced protein synthesis, changes in gene transcription and increased myofibrillar assembly [79].

Pharmacological activation of AMPK inhibits protein synthesis and gene transcription associated with cardiac hypertrophy [80,81]. Inactivation of AMPK in neonatal rat cardiomyocytes is permissive to development of hypertrophy [82]. This is denoted by AMPK ability to inhibit mTOR signalling [80]. Similarly, a decrease in AMPK activity exacerbates hypertrophic growth and heart failure following transverse aortic constriction [83].

The role of AMPK activation during the progression of left ventricular hypertrophy $(\mathrm{LVH})$ remains controversial, since it stimulates a response that in some cases may be adaptive, while in others, maladaptive. AMPK is activated in models of chronic pressure overload and linked to a switch in substrate preference to glucose, by an underlying increase of GLUT4 in the plasma membrane [84]. In this model, increased glucose uptake and increased AMPK activity are associated with the development of cardiac hypertrophy [85]. In contrast, in a model of spontaneously hypertensive rats AMPK activation is linked to inhibition of LVH development [86]. The effect 
on metabolic pathways was not examined in this model. It is very likely, that the cardio-protective effect of AMPK activation in this model is mediated by inhibition of pro-hypertrophic signaling. This is mainly achieved by targeting the mTOR pathway $[81,82]$.

\section{Concluding Remarks}

AMPK signalling sits at the nexus of cellular energy sensing and homeostasis in a variety of cell types. It is particularly important in the heart, a highly energy-consuming organ. Alterations in AMPK signalling can trigger a series of downstream molecular events that alter the way heart responds to external stimuli, particularly those stimuli that lead to energetic stress. Depending on the nature of the energetic stress, long- vs. short-term or pathological vs. physiological, AMPK signalling can either promote or attenuate the development of cardiac disease. External factors, such as anti-cancer drugs. deregulate cardiac AMPK signalling leading to unwanted and potentially harmful cardiovascular side effects. Future studies are needed to fully characterize all anti-tumor agents that affect cardiac AMPK signalling and negatively impact cardiac health. Pharmacological modification of currently available drugs and development of new cancer therapeutics is a key step to more effective treatment regimens.

\section{Acknowledgements}

This work was supported by NIH grant (HL098256), by a National Mentored Research Science Development Award (K01 AR052840) and Independent Scientist Award (K02 HL105799) from the NIH awarded to J.P. Konhilas. Support was received from the Sarver Heart Center at the University of Arizona.

\section{References}

1. Stapleton D, Mitchelhill KI, Gao G, Widmer J, Michell BJ, et al.(1996) Mammalian AMP-activated protein kinase subfamily. The Journal of biological chemistry 271:611-614

2. Thornton C, Snowden MA, Carling D (1998) Identification of a novel AMPactivated protein kinase beta subunit isoform that is highly expressed in skeletal muscle. J Biol Chem 273: 12443-12450.

3. Cheung PC, Salt IP, Davies SP, Hardie DG, Carling D (2000) Characterization of AMP-activated protein kinase gamma-subunit isoforms and their role in AMP binding. Biochem J 346 Pt 3: 659-669.

4. Hawley SA, Davison M, Woods A, Davies SP, Beri RK, et al. (1996) Characterization of the AMP-activated protein kinase kinase from rat liver and identification of threonine 172 as the major site at which it phosphorylates AMPactivated protein kinase. J Biol Chem 271: 27879-27887.

5. Woods A, Vertommen D, Neumann D, Turk R, Bayliss J, et al. (2003) Identification of phosphorylation sites in AMP-activated protein kinase (AMPK) for upstream AMPK kinases and study of their roles by site-directed mutagenesis. J Biol Chem 278: 28434-28442.

6. Pang T, Xiong B, Li JY, Qiu BY, Jin GZ, et al. (2007) Conserved alpha-helix acts as auto inhibitory sequence in AMP-activated protein kinase alpha subunits. $J$ Biol Chem 282: 495-506.

7. Chen L, Jiao ZH, Zheng LS, Zhang YY, Xie ST, et al. (2009) Structural insight into the auto inhibition mechanism of AMP-activated protein kinase. Nature 459: 1146-1149.

8. Xiao B, Sanders MJ, Underwood E, Heath R, Mayer FV, et al. (2011) Structure of mammalian AMPK and its regulation by ADP. Nature 472: 230-233.

9. Calabrese MF, Rajamohan F, Harris MS, Caspers NL, Magyar R, et al. (2014) Structural Basis for AMPK Activation: Natural and Synthetic Ligands Regulate Kinase Activity from Opposite Poles by Different Molecular Mechanisms. Structure 22: 1161-1172.

10. Quentin T, Kitz J, Steinmetz M, Poppe A, Bar K, et al. (2011) Different expression of the catalytic alpha subunits of the AMP activated protein kinase-an immunohistochemical study in human tissue. Histology and histopathology 26: 589-596.

11. Polekhina G, Gupta A, Michell BJ, van Denderen B, Murthy S, et al. (2003) AMPK beta subunit targets metabolic stress sensing to glycogen. Curr Biol 13: $867-871$.
12. McBride A, Ghilagaber S, Nikolaev A, Hardie DG (2009) The glycogen-binding domain on the AMPK beta subunit allows the kinase to act as a glycogen sensor. Cell Metab 9: 23-34.

13. Moffat C, Harper ME (2010) Metabolic functions of AMPK: Aspects of structure and of natural mutations in the regulatory gamma subunits. IUBMB Life 62: 739-745.

14. Dasgupta B, Ju JS, Sasaki Y, Liu X, Jung SR, et al. (2012) The AMPK î22 subunit is required for energy homeostasis during metabolic stress. Mol Cell Biol 32: 2837-2848.

15. Day P, Sharff A, Parra L, Cleasby A, Williams M, et al. (2007) Structure of a CBS-domain pair from the regulatory gamma1 subunit of human AMPK in complex with AMP and ZMP. Acta Crystallogr D Biol Crystallogr 63: 587-596.

16. Xiao B, Heath R, Saiu $P$, Leiper FC, Leone $P$, et al. (2007) Structural basis for AMP binding to mammalian AMP-activated protein kinase. Nature 449: 496500 .

17. Mahlapuu M, Johansson C, Lindgren K, Hjalm G, Barnes BR, et al. (2004) Expression profiling of the gamma-subunit isoforms of AMP-activated protein kinase suggests a major role for gamma3 in white skeletal muscle. American journal of physiology Endocrinology and metabolism 286:E194-200.

18. Xiao B, Sanders MJ, Carmena D, Bright NJ, Haire LF, et al. (2013) Structura basis of AMPK regulation by small molecule activators. Nat Commun 4: 3017.

19. Suter M, Riek U, Tuerk R, Schlattner U, Wallimann T, et al. (2006) Dissecting the role of 5'-AMP for allosteric stimulation, activation, and deactivation of AMP-activated protein kinase. J Biol Chem 281: 32207-32216.

20. Zhu L, Chen L, Zhou XM, Zhang YY, Zhang YJ, et al. (2011) Structural insights into the architecture and allostery of full-length AMP-activated protein kinase. Structure 19: 515-522.

21. Anderson KA, Means RL, Huang QH, Kemp BE, Goldstein EG, et al. (1998) Components of a calmodulin-dependent protein kinase cascade. Molecular cloning, functional characterization and cellular localization of $\mathrm{Ca} 2+/$ calmodulindependent protein kinase kinase beta. The Journal of biological chemistry 273:31880-31889

22. Hawley SA, Boudeau J, Reid JL, Mustard KJ, Udd L, et al. (2003) Complexes between the LKB1 tumor suppressor, STRAD alpha/beta and MO25 alpha/beta are upstream kinases in the AMP-activated protein kinase cascade. J Biol 2: 28.

23. Woods A, Johnstone SR, Dickerson K, Leiper FC, Fryer LG, et al. (2003) LKB1 is the upstream kinase in the AMP-activated protein kinase cascade. Curr Biol 13: 2004-2008.

24. Boudeau J, Baas AF, Deak M, Morrice NA, Kieloch A, et al. (2003) MO25alpha/ beta interact with STRADalpha/beta enhancing their ability to bind, activate and localize LKB1 in the cytoplasm. EMBO J 22: 5102-5114.

25. Park S, Scheffler TL, Rossie SS, Gerrard DE (2013) AMPK activity is regulated by calcium-mediated protein phosphatase 2 A activity. Cell Calcium 53: 217223.

26. Wang MY, Unger RH (2005) Role of PP2C in cardiac lipid accumulation in obese rodents and its prevention by troglitazone. Am J Physiol Endocrinol Metab 288: E216-221.

27. Lin YY, Kiihl S, Suhail Y, Liu SY, Chou YH, et al. (2012) Functional dissection of lysine deacetylases reveals that HDAC1 and p300 regulate AMPK. Nature 482: 251-255.

28. Oakhill JS, Chen ZP, Scott JW, Steel R, Castelli LA, et al. (2010) $\beta$-Subunit myristoylation is the gatekeeper for initiating metabolic stress sensing by AMPactivated protein kinase (AMPK). Proceedings of the National Academy of Sciences of the United States of America 107:19237-19241.

29. Dyck JR, Lopaschuk GD (2006) AMPK alterations in cardiac physiology and pathology: Enemy or ally? J Physiol 574: 95-112.

30. Lyytinen H, Pukkala E, Ylikorkala O (2009) Breast cancer risk in postmenopausal women using estradiol-progestogen therapy. Obstet Gynecol 113: 65-73.

31. Park SH, Gammon SR, Knippers JD, Paulsen SR, Rubink DS, et al. (2002) Phosphorylation-activity relationships of AMPK and acetyl-CoA carboxylase in muscle. J Appl Physiol (1985) 92: 2475-2482.

32. McGarry JD, Brown NF (1997) The mitochondrial carnitine palmitoyltransferase system. From concept to molecular analysis. Eur J Biochem 244: 1-14. 
33. Chabowski A, Momken I, Coort SL, Calles-Escandon J, Tandon NN, et al. (2006) Prolonged AMPK activation increases the expression of fatty acid transporters in cardiac myocytes and perfused hearts. Mol Cell Biochem 288: 201-212.

34. Luiken JJ, Coort SL, Willems J, Coumans WA, Bonen A, et al. (2003) Contraction-induced fatty acid translocase/CD36 translocation in rat cardiac myocytes is mediated through AMP-activated protein kinase signaling. Diabetes 52: 1627-1634.

35. Thomson DM, Winder WW (2009) AMP-activated protein kinase control of fat metabolism in skeletal muscle. Acta Physiol (Oxf) 196: 147-154.

36. McGee SL, van Denderen BJ, Howlett KF, Mollica J, Schertzer JD, et al (2008) AMP-activated protein kinase regulates GLUT4 transcription by phosphorylating histone deacetylase 5. Diabetes 57: 860-867.

37. Habegger KM, Hoffman NJ, Ridenour CM, Brozinick JT, Elmendorf JS (2012) AMPK enhances insulin-stimulated GLUT4 regulation via lowering membrane cholesterol. Endocrinology 153: 2130-2141.

38. Abbud W, Habinowski S, Zhang JZ, Kendrew J, Elkairi FS, et al. (2000) Stimulation of AMP-activated protein kinase (AMPK) is associated with enhancement of Glut1-mediated glucose transport. Arch Biochem Biophys 380: $347-352$.

39. Marsin AS, Bertrand L, Rider MH, Deprez J, Beauloye C, et al. (2000) Phosphorylation and activation of heart PFK-2 by AMPK has a role in the stimulation of glycolysis during ischaemia. Curr Biol 10: 1247-1255.

40. Musi N, Hirshman MF, Arad M, Xing Y, Fujii N, et al. (2005) Functional role of AMP-activated protein kinase in the heart during exercise. FEBS Lett 579 : 2045-2050.

41. Halse R, Fryer LG, McCormack JG, Carling D, Yeaman SJ (2003) Regulation of glycogen synthase by glucose and glycogen: A possible role for AMP-activated protein kinase. Diabetes 52: 9-15.

42. Bultot L, Guigas B, Von Wilamowitz-Moellendorff A, Maisin L, Vertommen D, et al. (2012) AMP-activated protein kinase phosphorylates and inactivates liver glycogen synthase. Biochem J 443: 193-203.

43. Hemminki A, Markie D, Tomlinson I, Avizienyte E, Roth S, et al.(1998) A serine/ threonine kinase gene defective in Peutz-Jeghers syndrome. Nature 391:184187.

44. Jenne DE, Reimann H, Nezu J, Friedel W, Loff S, et al. (1998) Peutz-Jeghers syndrome is caused by mutations in a novel serine threonine kinase. Nat Genet 18: $38-43$.

45. Katajisto P, Vallenius T, Vaahtomeri K, Ekman N, Udd L, et al. (2007) The LKB1 tumor suppressor kinase in human disease. Biochim Biophys Acta 1775: 63-75

46. DeBerardinis RJ, Lum JJ, Hatzivassiliou G, Thompson CB (2008) The biology of cancer: Metabolic reprogramming fuels cell growth and proliferation. Cell Metab 7: 11-20.

47. Vander Heiden MG, Cantley LC, Thompson CB (2009) Understanding the Warburg effect: The metabolic requirements of cell proliferation. Science 324 1029-1033.

48. Deberardinis RJ, Sayed N, Ditsworth D, Thompson CB (2008) Brick by brick: Metabolism and tumor cell growth. Curr Opin Genet Dev 18: 54-61.

49. Faubert B, Boily G, Izreig S, Griss T, Samborska B, et al. (2013) AMPK is a negative regulator of the Warburg effect and suppresses tumor growth in vivo. Cell Metab 17: 113-124.

50. Faubert B, Vincent EE, Griss T, Samborska B, Izreig S, et al. (2014) Loss of the tumor suppressor LKB1 promotes metabolic reprogramming of cancer cells via HIF-1a Proc Natl Acad Sci USA 111: 2554-2559.

51. Park HU, Suy S, Danner M, Dailey V, Zhang Y, et al. (2009) AMP-activated protein kinase promotes human prostate cancer cell growth and survival. Molecular cancer therapeutics 8:733-741.

52. Ríos M, Foretz M, Viollet B, Prieto A, Fraga M, et al. (2013) AMPK activation by oncogenesis is required to maintain cancer cell proliferation in astrocytic tumors. Cancer Res 73: 2628-2638.

53. Jeon SM, Chandel NS, Hay N (2012) AMPK regulates NADPH homeostasis to promote tumour cell survival during energy stress. Nature 485: 661-665.

54. Tennakoon JB, Shi Y, Han JJ, Tsouko E, White MA, et al. (2014) Androgens regulate prostate cancer cell growth via an AMPK-PGC-1 $1 \hat{\mid} \pm$-mediated metabolic switch. Oncogene 33: 5251-5261.

55. Leprivier G, Remke M, Rotblat B, Dubuc A, Mateo AR, et al. (2013) The eEF2 kinase confers resistance to nutrient deprivation by blocking translation elongation. Cell 153: 1064-1079.

56. Laderoute KR, Calaoagan JM, Chao WR, Dinh D, Denko N, et al. (2014) 5'-AMP-activated protein kinase (AMPK) supports the growth of aggressive experimental human breast cancer tumors. J Biol Chem 289: 22850-22864.

57. Zulato E, Bergamo F, De Paoli A, Griguolo G, Esposito G, et al. (2014) Prognostic significance of AMPK activation in advanced stage colorecta cancer treated with chemotherapy plus bevacizumab. Br J Cancer 111: 25-32.

58. Zheng L, Yang W, Wu F, Wang C, Yu L, et al.(2013) Prognostic significance of AMPK activation and therapeutic effects of metformin in hepatocellular carcinoma. Clinical cancer research: an official journal of the American Association for Cancer Research 19:5372-5380.

59. Hadad SM, Baker L, Quinlan PR, Robertson KE, Bray SE, et al. (2009) Histological evaluation of AMPK signalling in primary breast cancer. BMC Cancer 9: 307.

60. Inoki K, Zhu T, Guan KL (2003) TSC2 mediates cellular energy response to control cell growth and survival. Cell 115: 577-590.

61. Gwinn DM, Shackelford DB, Egan DF, Mihaylova MM, Mery A, et al. (2008) AMPK phosphorylation of raptor mediates a metabolic checkpoint. Mol Cell 30: $214-226$

62. Dong LX, Sun LL, Zhang X, Pan L, Lian LJ, et al. (2013) Negative regulation of mTOR activity by LKB1-AMPK signaling in non-small cell lung cancer cells. Acta Pharmacol Sin 34: 314-318.

63. Green AS, Chapuis N, Maciel TT, Willems L, Lambert M, et al. (2010) The LKB1/AMPK signaling pathway has tumor suppressor activity in acute myeloid leukemia through the repression of mTOR-dependent oncogenic mRNA translation. Blood 116: 4262-4273.

64. Chou CC, Lee KH, Lai IL, Wang D, Mo X, et al. (2014) AMPK reverses the mesenchymal phenotype of cancer cells by targeting the Akt-MDM2-Foxo3a signaling axis. Cancer Res 74: 4783-4795.

65. Yung MM, Chan DW, Liu VW, Yao KM, Ngan HY (2013) Activation of AMPK inhibits cervical cancer cell growth through AKT/FOXO3a/FOXM1 signaling cascade. BMC Cancer 13: 327

66. Fox MM, Phoenix KN, Kopsiaftis SG, Claffey KP (2013) AMP-Activated Protein Kinase $\alpha 2$ Isoform Suppression in Primary Breast Cancer Alters AMPK Growth Control and Apoptotic Signaling. Genes Cancer 4: 3-14.

67. Lee CW, Wong LL, Tse EY, Liu HF, Leong VY, et al. (2012) AMPK promotes p53 acetylation via phosphorylation and inactivation of SIRT1 in liver cancer cells. Cancer Res 72: 4394-4404.

68. Ewer MS, Ewer SM (2010) Cardiotoxicity of anticancer treatments: What the cardiologist needs to know. Nat Rev Cardiol 7: 564-575.

69. Hahn VS, Lenihan DJ, Ky B (2014) Cancer therapy-induced cardiotoxicity: Basic mechanisms and potential cardioprotective therapies. Journal of the American Heart Association 3:e000665.

70. Scott JM, Khakoo A, Mackey JR, Haykowsky MJ, Douglas PS, et al. (2011) Modulation of anthracycline-induced cardiotoxicity by aerobic exercise in breast cancer: current evidence and underlying mechanisms. Circulation 124:642-650.

71. Tokarska-Schlattner M, Zaugg M, da Silva R, Lucchinetti E, Schaub MC, et al. (2005) Acute toxicity of doxorubicin on isolated perfused heart: response of kinases regulating energy supply. American journal of physiology Heart and circulatory physiology $289: \mathrm{H} 37-47$.

72. Gratia S, Kay L, Potenza L, Seffouh A, Novel-Chaté V, et al. (2012) Inhibition of AMPK signalling by doxorubicin: at the crossroads of the cardiac responses to energetic, oxidative, and genotoxic stress. Cardiovasc Res 95: 290-299.

73. Manning G, Whyte DB, Martinez R, Hunter T, Sudarsanam S (2002) The protein kinase complement of the human genome. Science 298:1912-1934.

74. Chu TF, Rupnick MA, Kerkela R, Dallabrida SM, Zurakowski D, et al. (2007) Cardiotoxicity associated with tyrosine kinase inhibitor sunitinib. Lancet 370 2011-2019.

75. Kerkela R, Woulfe KC, Durand JB, Vagnozzi R, Kramer D, et al. (2009) 
Citation: Lipovka Y, Konhilas JP (2015) AMP-Activated Protein Kinase Signalling in Cancer and Cardiac Hypertrophy. Cardiovasc Pharm Open Access 4: 154. doi:10.4172/2329-6607.1000154

Sunitinib-induced cardiotoxicity is mediated by off-target inhibition of AMPactivated protein kinase. Clin Transl Sci 2: 15-25.

76. Shell SA, Lyass L, Trusk PB, Pry KJ, Wappel RL, et al. (2008) Activation of AMPK is necessary for killing cancer cells and sparing cardiac cells. Cell Cycle 7: $1769-1775$.

77. Spector NL, Yarden Y, Smith B, Lyass L, Trusk P, et al.( 2007) Activation of AMP-activated protein kinase by human EGF receptor 2/EGF receptor tyrosine kinase inhibitor protects cardiac cells. Proceedings of the National Academy of Sciences of the United States of America 104:10607-10612.

78. Sambandam N, Lopaschuk GD, Brownsey RW, Allard MF (2002) Energy metabolism in the hypertrophied heart. Heart Fail Rev 7: 161-173.

79. Sugden PH, Clerk A (1998) Cellular mechanisms of cardiac hypertrophy. J Mo Med (Berl) 76: 725-746.

80. Stuck BJ, Lenski M, Böhm M, Laufs U (2008) Metabolic switch and hypertrophy of cardiomyocytes following treatment with angiotensin II are prevented by AMP-activated protein kinase. J Biol Chem 283: 32562-32569.

81. Chan AY, Dolinsky VW, Soltys CL, Viollet B, Baksh S, et al. (2008) Resveratrol inhibits cardiac hypertrophy via AMP-activated protein kinase and Akt. J Biol Chem 283: 24194-24201.
82. Chan AY, Soltys CL, Young ME, Proud CG, Dyck JR (2004) Activation of AMPactivated protein kinase inhibits protein synthesis associated with hypertrophy in the cardiac myocyte. J Biol Chem 279: 32771-32779.

83. Liao Y, Takashima S, Maeda N, Ouchi N, Komamura K, et al. (2005) Exacerbation of heart failure in adiponectin-deficient mice due to impaired regulation of AMPK and glucose metabolism. Cardiovasc Res 67: 705-713.

84. Tian R, Musi N, D'Agostino J, Hirshman MF, Goodyear LJ (2001) Increased adenosine monophosphate-activated protein kinase activity in rat hearts with pressure-overload hypertrophy. Circulation 104:1664-1669.

85. Nascimben L, Ingwall JS, Lorell BH, Pinz I, Schultz V, et al. (2004) Mechanisms for increased glycolysis in the hypertrophied rat heart. Hypertension 44: 662667.

86. Dolinsky VW, Morton JS, Oka T, Robillard-Frayne I, Bagdan M, et al. (2010) Calorie restriction prevents hypertension and cardiac hypertrophy in the spontaneously hypertensive rat. Hypertension 56: 412-421. 